\title{
A boy with developmental delay and a maternally inherited deletion in 15q11q13
}

\author{
M King, C Hardy, B Asenbauer, M Kilpatrick, T Webb
}

The Children's

Hospital, Temple

Street, Dublin 1,

Ireland

M King

B Asenbauer

Department of

Clinical Genetics,

University of

Birmingham,

Birmingham

Maternity Hospital,

Edgbaston,

Birmingham B15 2TG,

UK

C Hardy

M Kilpatrick

T Webb

Correspondence to: Dr Webb.

Received 15 May 1995 Revised version
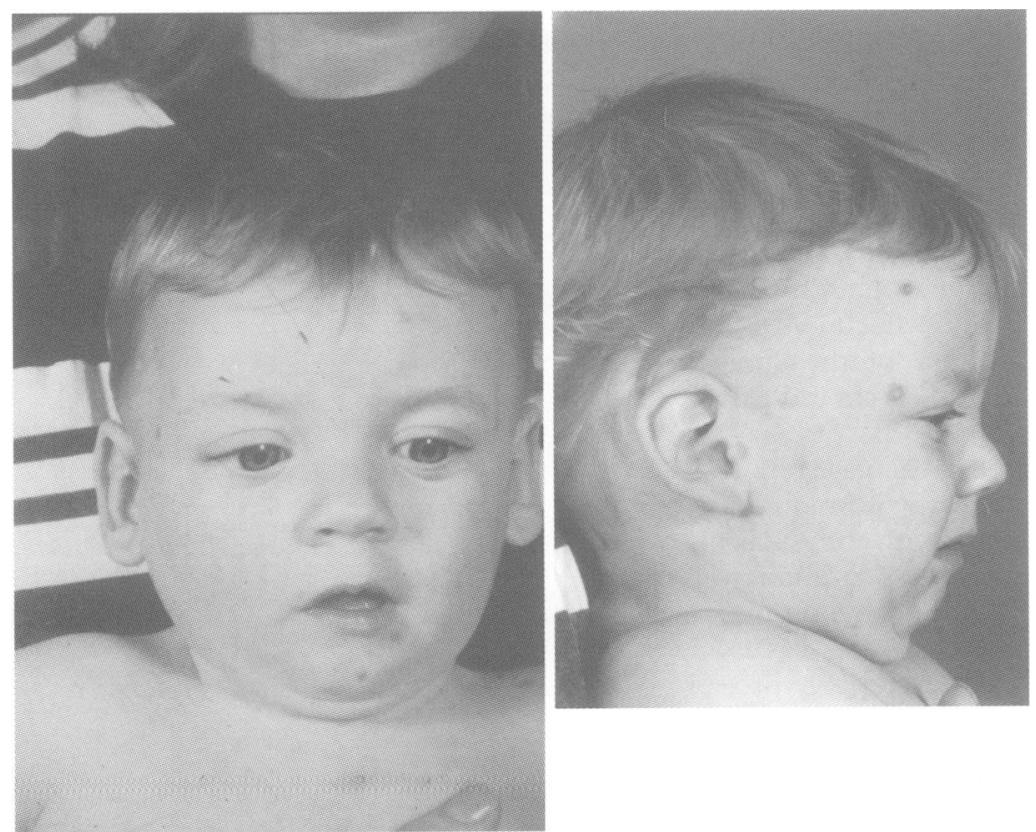

Figure 1 Facial appearance of the proband showing that he does not have the features of either Angelman syndrome or Prader-Willi syndrome.

Cytogenetic deletions involving $15 \mathrm{q} 11 \mathrm{q} 13$ are associated with both Prader-Willi syndrome (PWS) ${ }^{12}$ and Angelman syndrome (AS). ${ }^{3}$ The origin of the deleted chromosome is paternal in PWS and maternal in AS, which is characterised by severe developmental delay, an ataxic gait, hand flapping, inappropriate laughter, tongue thrusting, and seizures. ${ }^{4}$

Molecular studies have confirmed the parental origin of the deleted chromosome 15 in both syndromes and have also shown frequent cases of maternal uniparental disomy in nondeletion PWS 5 and occasional paternal uniparental disomy in $\mathrm{AS},{ }^{6}$ confirming that the region is imprinted. Molecular investigation has also determined that the Prader-Willi critical region (PWSCR) is located proximal to that for AS (ASCR), but that the majority of cases

\begin{abstract}
$A$ boy was referred at 8 weeks of age for failure to thrive. Cytogenetic and molecular studies showed that he had a large proximal deletion of the maternally derived chromosome 15q. He did not have Angelman syndrome, but at 2 years of age was severely globally delayed. He died at $2 \frac{1}{2}$ years of age.
\end{abstract}

(f Med Genet 1996;33:422-425)

Key words: developmental delay; chromosome 15; deletion. 

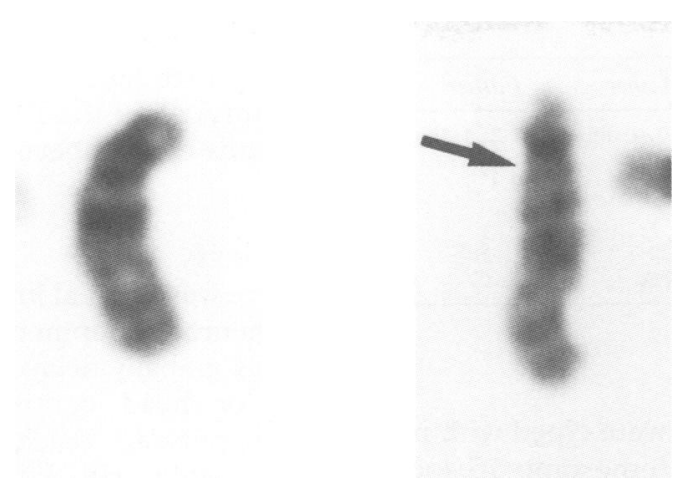

Figure 2 Two chromosomes 15 from the proband. The abnormal, deleted homologue is on the left hand side of the pair. Band $15 q 12$ is clearly visible in the normal homologue (arrowed) but is deleted in the abnormal chromosome 15.

In urine the following were normal: sulphite test, amino acids, bile acids, and organic acids.

In cerebrospinal fluid the following were normal: protein, amino acids, and lactate.

\section{Imaging}

Abdominal and cerebral ultrasound, skeletal survey, and CT brain scan were all normal. However, MRI of the brain showed generalised cerebral atrophy. There was a symmetrical area of abnormal myelination involving the deep white matter around the posterior horns of the lateral ventricles.

\section{Electrophysiology}

Visual evoked responses were absent while electroretinogram was of small amplitude. Electroencephalogram (EEG) between the ages of 9 weeks and 2 years showed diffuse high voltage slow activity $(400 \mu \mathrm{v})$ with associated spike and slow wave discharge during sleep. The typical EEG features of AS were not seen.

\section{CYTOGENETIC STUDIES}

Prometaphase chromosomes were obtained from blood lymphocytes both by synchronisation and by intercalation of DNA with ethidium bromide. The proband had the karyotype 46,XY,del(15)(q11q13)(mat). The deletion was observed to be larger than that generally found in either Prader-Willi or Angelman syndromes (fig 2). Study of polymorphisms associated with the short arm of chromosome 15 showed the deleted chromosome to be maternal in origin. No other additional karyotypic abnormality was observed.
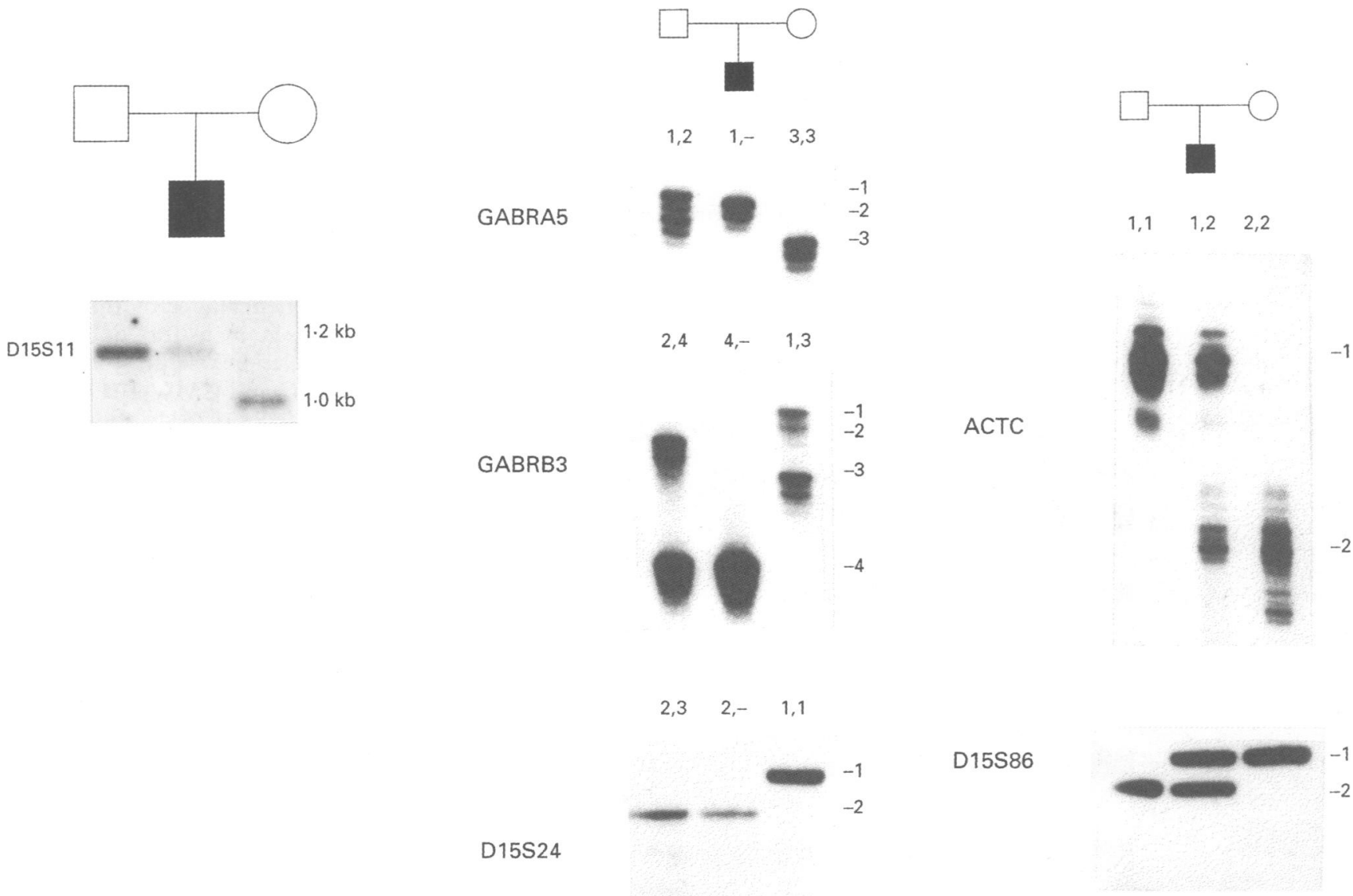

Figure 3 Southern blot of RFLP analysis at D15S11 showing lack of maternal inheritance in the proband (left). Autoradiographs showing maternally derived deletions in the proband at three loci in 15q11q13 (GABRA5, GABRB3, D15S24) (centre) and the presence of both maternal and paternal contributions at loci ACTC and D15S86 (pMS620) (right). 
Informative haplotypes at loci within the 15q11q13 region for the proband and his parents

\begin{tabular}{llll}
\hline Locus & Proband & Mother & Father \\
\hline D15S11 & $1 \cdot 2,-\mathrm{kb}$ & $1 \cdot 0,1 \cdot 0 \mathrm{~kb}$ & $1 \cdot 2,1 \cdot 2 \mathrm{~kb}$ \\
D15S11 & $3,-$ & 2,4 & 1,3 \\
D15S128 & $4,-$ & 1,3 & 2,4 \\
D15S113 & $2,-$ & 3,3 & 1,2 \\
GABRB3 & $3,-$ & 1,2 & 2,3 \\
GABRA5 & $1,-$ & 3,3 & 1,2 \\
D15S24 & B, - & A, A & B, C \\
\hline
\end{tabular}

\section{MOLECULAR STUDIES}

The boy and his parents were typed with polymorphic markers for chromosome 15 loci to define the deletion at the molecular level (table). As his father was homozygous for the $1.2 \mathrm{~kb}$ band and his mother homozygous for the $1.0 \mathrm{~kb}$ band, while the proband showed only the $1.2 \mathrm{~kb}$ band, RFLP analysis using RsaI for locus D15S11, ${ }^{10}$ which lies within the Prader-Willi chromosomal region (PWCR), showed no maternally derived material in the proband (fig 3, left), as did analysis with microsatellite markers for D15S11, D15S128, and D15S113 loci, and the GABR 33 and GABRA5 genes (fig 3, centre), which have also been assigned to the Angelman/Prader-Willi region. ${ }^{11} 12$ Analysis of the D15S24 locus, which lies distal to the PWCR, ${ }^{713}$ again showed no maternally derived material in the proband (fig 3, centre). Analysis with a CA repeat marker for the cardiac muscle actin gene locus (ACTC), ${ }^{14}$ which lies distal to D15S24, however, did show the presence of a maternally derived allele (fig 3, right). This defined the distal boundary of the deletion as between D15S24 and ACTC. The family was also fully informative for the telomeric marker pMS620 (D15S86) which showed the presence of both maternally and paternally derived alleles in the proband (fig 3,

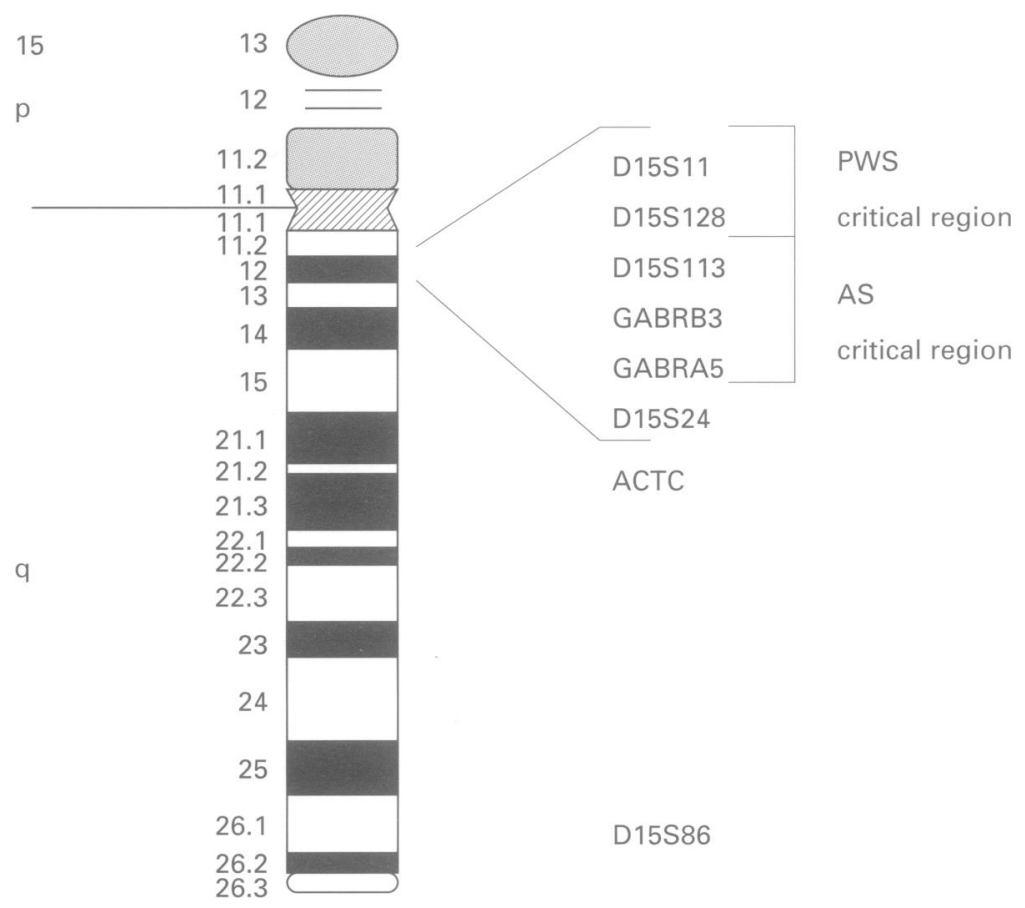

Figure 4 The left hand bracket encompasses six loci in 15q11q13 all of which were shown to be deleted. The more distal loci ACTC, D15S86, and D15S87 showed biparental inheritance. The right hand bracket shows the common breakpoints encompassing the PWS and AS critical regions. right). Fig 4 shows an ideogram of chromosome 15 with deleted informative loci in $15 \mathrm{q} 11 \mathrm{q} 13$ shown in order. ${ }^{15}$ It can be seen that the deletion includes all of the PWS/AS critical region and extends distally beyond it.

\section{PROGRESS}

There was gradual improvement in feeding but no neurodevelopment. At $2 \frac{1}{2}$ years he was severely globally delayed. He had no head righting or head control and was not sitting unsupported, reaching, smiling, or communicating. He did not make contact with people or display any interest in his surroundings. The dyskinesia remained prominent. He had developed mild epilepsy which was controlled by sodium valproate.

At $2 \frac{1}{2}$ years he was found dead in his cot. General necropsy did not show any abnormality. Neuropathological examination showed features of mild hypoxic ischaemic encephalopathy of recent onset. There was also mild non-obstructive ventricular dilatation. In particular there was normal cortex, subcortical white matter, striatum, brain stem, and cerebellum with no evidence of demyelination or dysmyelination. It is likely that death occurred as a result of prolonged apnoea during a seizure.

\section{Discussion}

A boy with gross developmental delay but without Angelman syndrome has been found to have a maternally derived deletion of chromosome 15 at $15 \mathrm{q} 11 \mathrm{q} 13$. The deletion was microscopically very large and was shown by molecular methods to include D15S24, a locus which is known to lie distal to the PWS/ASCR and is very rarely deleted in either Angelman or Prader-Willi syndromes. ${ }^{13}$ The deletion in this proband was not found to extend into $15 \mathrm{q} 21$ either cytogenetically or by the finding of heterozygosity at the locus for ACTC. The distal limit of the deletion was thus defined as lying between ACTC and CMW-1 (D15S24). Proximally it included D15S11, shown both by Southern blotting and by PCR methodology. Paternal uniparental isodisomy was excluded both cytogenetically and by the inheritance of a maternal contribution in D15S86 and ACTC. A combination of cytogenetic and molecular estimations of the size of this deletion suggests that it may represent at least $10 \%$ of the total length of chromosome 15 or approximately 10 megabases and extend beyond the imprinted region associated with Prader-Willi and Angelman syndromes. The severity of the clinical symptoms culminating in the death of the proband is most probably consequent upon the size of the deletion.

This would, however, imply that haploid insufficiency of an important gene located between D15S12 and ACTC could have such dire consequences or that there are further imprinted genes lying beyond D15S12.

The combination of clinical signs in this case has not, to our knowledge, been reported in association with deletion of maternally derived chromosome 15q11q13. In particular, the lack 
of any neurodevelopment whatsoever, early death, striking dyskinesia, and eye findings were not typical of Angelman syndrome. In addition, the characteristic craniofacial, neurological, and EEG features of this syndrome were not present. Although a maternally derived deletion in $15 \mathrm{q} 11 \mathrm{q} 13$ which encompasses the critical region would be expected to result in a phenotype with manifestations of Angelman syndrome, the influence of an increased chromatin loss is concomitant with a more severe phenotype and the early death of this boy, so that direct developmental comparisons were precluded.

1 Ledbetter DH, Riccardi VM, Airhart SD, Strobel RJ, Keenan SB, Crawford JD. Deletions of chromosome 15 as a cause of Prader-Willi syndrome. $N$ Engl $\mathcal{F}$ Med 1981; 304:325-9.

2 Butler MG, Palmer CG. Parental origin of chromosome 15 deletion in Prader Willi syndrome. Lancet 1983;i:1285-6.

3 Williams CA, Zori RT, Stone JW, Gray BA, Cantu ES, Ostrer H. Maternal origin of 15q11-13 deletions in Angelman syndrome suggest a role for genomic imprinting. $\mathrm{Am} f$ syndrome suggest a role for genomic imprinting. Am $\mathcal{F}$
Med Genet 1990;35:350-3.

Clayed Genet 199:35:350-3. Genet 1992;29:412-5.

5 Nicholls RD, Knoll JHM, Butler MG, Karam S, Lalande M Genetic imprinting suggested by maternal heterodisomy in non-deletion Prader-Willi syndrome. Nature 1989;342:

6 Malcolm S, Clayton-Smith J, Nichols M, et al. Uniparenta disomy in Angelman's syndrome. Lancet 1991;337:694-7.

7 Kuwano A, Mutirangura A, Dittrich B, et al. Molecular dissection of the Prader Willi/Angelman syndrome region (15q11-13) by YAC cloning and FISH analysis. Hum Mol Genet 1992;1:417-25.

8 Rinchik EM, Bultman SJ, Horsthemke B, et al. A gene for the mouse pink-eyed dilution locus and for human type II oculocutaneous albinism. Nature 1993;361:72-6.

9 Galan F, Aguilar MS, Gonzalez J, et al. Interstitial 150 deletion without a classic Prader-Willi phenotype. Am f Med Genet 1991:38:532-4.

10 Donlon TA, Lalande M, Wyman A, Bruns G, Latt SA. Isolation of molecular probes associated with the chromosome 15 instability in the Prader-Willi syndrome. Proc Natl Acad Sci USA 1986;83:4408-12.

11 Mutirangura A, Ledbetter SA, Kuwano A, Chinault AC Ledbetter DH. Dinucleotide repeat polymorphism at the $\mathrm{GABA}_{\mathrm{A}}$ receptor $\beta 3$ (GABRB3) locus in the Angelman Prader-Willi region (AS/PWS) of chromosome 15. Hum Mol Genet 1992;1:67.

12 Glatt KA, Sinnett D, Lalande M. Dinucleotide repeat polymorphism at the $\mathrm{GABA}_{\mathrm{A}}$ receptor $\alpha 5$ (GABRA5) locus at chromosome 15q11-q13. Hum Mol Genet 1992;1:348.

13 Knoll JHM, Nicholls RD, Magenis RE, et al. Angelman syndrome: three molecular classes identified with chromosome 15q11q13-specific DNA markers. Am 7 Hum Genet 1990;47:149-55.

14 Litt M, Luty JA. A hypervariable microsatellite revealed by in vitro amplification of a dinucleotide repeat within the cardiac muscle actin gene. Am f Hum Genet 1989;44 397-401.

15 Robinson WP, Lalande $M$. Sex-specific meiotic recombination in the Prader-Willi/Angelman syndrome imprinted region. Hum Mol Genet 1995;4:801-6. 